\title{
Life Of Plants In Space: A Challenging Mission For Tiny Greens In An Everlasting Darkness
}

\section{Ecem Su KOÇKAYA ${ }^{1}$ Cemal ÜN ${ }^{1}$}

${ }^{1}$ Ege Üniversitesi Biyoteknoloji Anabilim Dal, esukockaya@gmail.com

1 Prof. Dr., Ege Üniversitesi, cemalun@ege.edu.tr

Geliş Tarihi/Received: 24.11.2021 Kabul Tarihi/Accepted: 25.01.2022 e-Yayım/e-Printed: 28.02.2022

DOI: $10.52995 /$ jass. 1027772

ORCID: 0000-0001-9568-641X ${ }^{1,}$ 0000-0002-4248-96712

\begin{abstract}
With the increased number of space related studies, it has become a significant study field in both dependable and long term biology based life support systems for long term space flights. Plants have been the major focus of this research. The capability of cultivate plants in space can help to provide astronauts with essential nutrients as well as improve their psychological health. Simulating the space environment, detailed gene analysis, and detailed growth analyzes reveal the effects of the space environment on plants. From the first photosynthetic organisms in the sea to today's terrestrial higher plants, they have survived millions of years on the Earth with the power of adaptations and evolution. Therefore, compared to the Earth, in the space environment, plants will react differently to decreased gravity, increased radiation rate, lost light source, and they will have altered stress gene regulation. In this review, which is about the adaptation of plants to the space environment, how plants react when they encounter stressful conditions that cause changes in their structures in the space environment and the results are discussed with various experiments. As a result, with using different plant species, it looks like even though these tiny greens faced with the hard condition in space environment they have shown a resistance mechanism to all these tough environments.
\end{abstract}

Keywords: Spaceflight, Astrobotany, Microgravity, Radiation, Light. 


\section{Uzay Ortamında Bitkilerde Yaşam: Ebedi Karanlıkta Minik Yeşillikler İçin Zorlu Bir Görev}

\section{ÖZET}

Uzayla ilgili çalışmaların artması ile beraber, uzun süreli uzay uçuşları için hem güvenilir hem de sürdürülebilir biyoloji temelli yaşam destek sistemleri önemli bir araştırma alanı haline gelmiştir. Bu çalışmaların en önemli odak noktası ise bitkiler olmuştur. Uzayda bitki yetiştirme yeteneği, astronotlara gerekli besinleri sağlamanın yanı sıra, psikolojik sağlıklarını iyileştirmeye de yardım eder. Uzay ortamının simülasyonu, detaylı gen analizleri ve detaylı büyüme analizleri, uzay ortamının bitkiler üzerindeki etkilerini ortaya koymaktadır. Denizdeki ilk fotosentetik organizmalardan günümüzün karasal yüksek bitkilerine kadar, adaptasyon ve evrimin gücüyle bitkiler, Dünya'da milyonlarca yıl hayatta kalmışlardır. Bu nedenle Dünya ile karşılaştırıldığında, uzay ortamında bitkiler, azalan yerçekimine, artan radyasyon oranına, kayıp ışık kaynağına farklı tepkiler verecek ve stres gen regülasyonunu değiştirecektir. Bitkilerin uzay ortamına adaptasyonunu konu alan bu derlemede, bitkilerin uzay ortamındaki yapılarında değişikliklere neden olan stresli koşullarla karşılaştıklarında nasıl tepki verdikleri ve sonuçları çeşitli deneylerle tartışılmıştır. Farklı bitki türleri kullanılarak yapılan çeşitli deneyler sonucunda bu minik yeşillikler uzay ortamındaki zorlu koşullarla karşı karşıya kalsalar da tüm bu zorlu ortamlara karşı bir direnç mekanizması göstermişlerdir.

Anahtar Kelimeler: Uzay Uçuşu, Astrobotanik, Mikro Yerçekimi, Radyasyon, Işı.k.

\section{INTRODUCTION}

Astrobotany is a new field of the research branch of science in which plants are studied under conditions that prevailing in spaceflight for helping to understand life on the space environment. After researchers embarked on spaceflights, the path of growing plants has been embarked on flights too (Barker \& Gilroy, 2017). There are two primary aims for cultivating plants in space. The first reason is that researchers can investigate the effect of gravity in the control of biological processes in spaceflight. As a result, we can be able to conduct experiments in a one kind of laboratory environment that would be impossible on Earth. Thus, we can find answers to three questions: Can plants grow safely in space? How can plant damage be minimized? What methods may use to improve their production? The second reason is that we can develop a bio-regenerative life support system to provide astronauts with food and psychological benefits during long-duration spaceflight (Vandenbrink \& Kiss, 2016). However, as a result of the experiments, it has been understood that working with plants in a life support system is not that easy.

Microgravity is one of the most serious problems in the space environment. It has a major role in plant growth and development and plant yield with both cellular and physiological effects on the plant. Cell wall-related processes have been reported to be disturbed in the microgravity environment, resulting in alterations in the gene regulation of cell wall-modifying proteins in Arabidopsis plants (Kitaya, 2019). Many biological functions 
that rely on directional sense are likewise disrupted by the microgravity environment. The root cannot grow downwards, and the stem cannot grow upwards in the absence of gravity. Gravity is more than just a sense of up and down, it offers much more to biological approaches. For example, natural convection, is provided by gravity on Earth. With an unbalanced temperature, free convection can occur naturally on Earth. However, under microgravity conditions in space, only a small amount of free convection would occur. Plant growth would be hampered by decreased convection because heat and gas exchanges on plant leaves would be constrained (Barker \& Gilroy, 2017). When plants leave the earth's safe and protective atmosphere, another member of "stressful components of the space environment" awaits these tiny greens in there. This member is radiation itself. Radiation is a type of energy that is produced or transmitted rays, electromagnetic waves, or particles. Thanks to the Earth's atmosphere and magnetic field, the biosphere and living things can be protected from radiation damage. However, the many radiation sources in space, as well as the lack of atmosphere and magnetosphere, can cause a wide range of negative effects on living organisms, ranging from chromosomal problems to morphological abnormalities. Light and warmth are the main environmental factors that affect plant survival, dry mass distribution, and crop yield. According to the Earth, the space environment has a low temperature and a lack of light, for these reasons, we can add these two circumstances to the list of factors that make plant life in space challenging (Rehman, 2017). Controllable light environment elements utilized in the space environment include factors for greatly affect plant growth, such as light intensity that impacts photosynthesis and plant morphology, light quality that predominantly affects morphology, and lighting length that affects plant dormancy and flower bud production. On the other hand, the primary function of temperature on plants is to ensure the persistence of biochemical reactions that necessary for plant physiology (Kitaya, 2019).

\section{EFFECT OF MICROGRAVITY ON PLANTS}

Gravity is a signal that plants use to organize their body plans as they evolve through life on Earth, providing a clue to the plant's directional movements. Gravity is used by plants to control and coordinate their development throughout their life cycle in order to optimize the availability of light, water, and nutrients. Also, gravity is necessary during germination to orient the plant so that the shoots grow upwards, and the roots develop downwards (Taiz \& Zeiger, 2008). 


\subsection{Effect of Microgravity on Root}

On Earth, the gravity vector is the fundamental determinant of root growth direction. The gravity vector is detected in the columella cells situated in the roots' core. The presence of starch-containing amyloplasts within these cells is the most important factor in the gravity response. Root tropisms arise in certain root areas due to variably controlled cell proliferation on opposing sides of the root tip. The buildup of auxin at the root tip causes this unequal growth. In a space environment, gravitational vectors exist in the same way as microgravity does. There are significant variances in gravity levels above the Moon: $0.17 \mathrm{~g}$, Mars: $0.38 \mathrm{~g}$, and Earth: $1 \mathrm{~g}$. For this reason, we need to learn more about the orientation stimulus and root growth response necessary to drive root development in the appropriate direction (Muthert, Izzo, Van Zanten \& Aronne, 2020). In addition, gravitropism is a coordinated process of differential growth carried out by the plant in response to gravity. When auxin accumulates in the plant's root and is produced in the columella cells, it causes a decrease in elongation and leads the root to bend in the direction of the gravity vector. Gravity perception occurs in the columella cells in the core of the root cap, which are specialized cells found in all flowering plants' roots and shoots. The amyloplasts located in statolites inside columella cells are the default gravity sensors. These are thick, starch-filled organelles that migrate within the cell reaction to gravity. With their high mass and starch content, they are deposited in aggregates within the cell in response to gravity. Auxin concentration gradients induce a growth response. This hormone is located in the root's lower regions rather than its upperparts. The root's response to gravitropism has been detected in a microgravity simulation environment. It has been found that the nucleus is more centrally located in statolith cells grown in microgravity than on Earth. Thus, it is assumed that the location of the nucleus is related to gravity (Muthert et al., 2020).

Mutant forms with lower bending reflexes in their roots were used in an experiment to generate more linear root growth as an alternative to microgravity condition. Only the shoots of complex plants are exposed to light in their natural growing environment, while the roots grow in the dark. However, using the traditional agar-plate culture system, both roots and shoots can be light-treated. Researchers claimed that light impacts root growth and responses, so they prefer to investigate the tropic effects using an agar medium. When Arabidopsis seedlings were cultivated on a rigid agar plate tilted $45^{\circ}$ degrees to the direction of gravity, the agar surface produced a wavy growth pattern, which appears to represent a barrier to vertical development. Researchers focused on Arabidopsis thaliana mutant plants to better understand the processes that produce root tip rotation and root twisting in 
response to obstacle contact. The Waw2 mutant is one of these altered plants. The Wav2 gene encodes a protein from the BUD Emergence 46 family, a transmembrane domain at the $\mathrm{N}$-terminus, and an a/b-hydrolase domain at the $\mathrm{C}$-terminus. Its mutants are more capable than wild-type Arabidopsis thaliana for not only tactile stimuli, but also gravity, light, touch, and hydrotropic simulation. Wav2-1 roots exhibited acute bending and a confined radius when gravitropic responses were examined using agar media. Wild-type roots, on the other hand, exhibited gradual bending and a significant radius of curvature (Table 1). When the phototropic response of the wav2-1 mutant was researched using a white light source for 24 hours, a slight but noticeable increase in curvature was observed with both right and left irradiation. In conclusion, while the wav2 mutant inhibits root tip rotation and thus negatively regulates stimulus-induced root bending, it is not adequate for sensing and responding to environmental stimuli. While the use of mutant forms has proven to be useful for specific parameters, space-based research is required to corroborate the findings in the genuine microgravity environment of space (Mochizuki et al., 2005).

Figure 1 Root Gravitropism of Arabidopsis thaliana in Wild Type (Left) and WAV2-1 Mutants (Right)

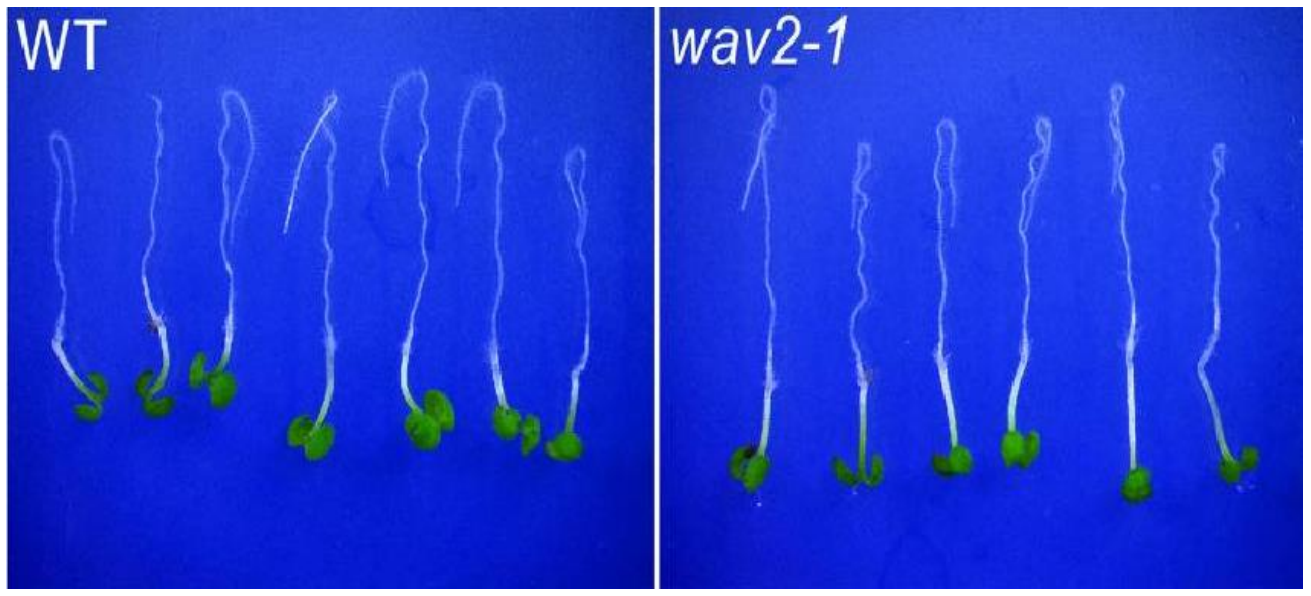

Source: Mochizuki et. al., 2005: 3.

\subsection{Effect of Microgravity on Leaf}

The Biomass Production System is a space shuttle equipped with a double mid-deck lock that is used to cultivate plants on a space station and it has four growth chambers (PGC). Each PGC governs the ambient temperature, humidity, light level, CO2 concentration, and matrix potential in the root zone. Each PGC has a light source that is cool white fluorescent lights. In an experiment that conducted by Stutte et al. (2006), the parameters of chloroplast development and cell morphology were investigated with the 21 day-old Triticum aestivum inside this shuttle in the space environment (Table 1). There was 
no difference in chloroplast density between $\mu \mathrm{g}$ (microgravity) and $1 \mathrm{~g}$ (earth gravity), but chloroplasts produced in $\mu \mathrm{g}$ conditions were slightly more rounded than chloroplasts produced in $1 \mathrm{~g}$ earth gravity controls. The growth of thylakoid membranes differed between the $\mu \mathrm{g}$ and $1 \mathrm{~g}$ samples, although there was no statistical difference in the quantity of thylakoids per grana stack. There was no change in starch content or chloroplast number between $1 \mathrm{~g}$ of control plants and those grown in the experiment under $\mu \mathrm{g}$. The transverse thickness of the leaf showed no difference. The linear length of the leaf has decreased in the $\mu \mathrm{g}$, and this decrease has grown proportionally with the plant's aging. Leaf cell density was found to be $13 \%$ higher in the $\mu \mathrm{g}$ condition than in the $1 \mathrm{~g}$ condition. There was no difference in leaf cell structures when gravity was changed. There was no difference in lignin content with increasing gravity. Based on these findings, we can conclude that simulated microgravity does not affect leaf development or photosynthetic function (Stutte et al., 2006).

Table 1: Cell Morphology and Chloroplast Development Characteristics of Triticum aestivum Leaves Grown in $\mu \mathrm{g}$ and $1 \mathrm{~g}$

\begin{tabular}{llll}
\hline Measurement & $\mu g$ & $1 g$ & $P>0.05$ \\
\hline Cell density $\left(\# / \mathrm{mm}^{2}\right)$ & 1,786 & 1,581 & $* * *$ \\
Cell area $\left(\mu \mathrm{m}^{2}\right)$ & 72.8 & 79.8 & $\mathrm{NS}$ \\
Chloroplast density (\#/cell) & 10.4 & 9.8 & $\mathrm{NS}$ \\
Chloroplast area $\left(\mu \mathrm{m}^{2}\right)$ & 0.534 & 0.522 & $\mathrm{NS}$ \\
Chloroplast L/W & 2.06 & 2.23 & $* *$ \\
Thylakoid density $(\# /$ grana) & 12.23 & 11.4 & $\mathrm{NS}$ \\
Thylakoid spacing $(\mathrm{nm})$ & 18.4 & 19.3 & $* *$ \\
\hline
\end{tabular}

Source: Stutte et al., 2006: 7.

\subsection{Effect of Microgravity on Plant Growth and Morphogenesis}

Plants must be the right size and form to carry out their physiological and biochemical functions effectively. Growth and morphogenesis are two closely related terms that reflect the total growth rates and directions between different regions of the plant. Throughout their life, plants have relied on gravity as the most stable and reliable signal since it always moves in the same direction. As a result, it is assumed that the stressful environment of space with microgravity conditions will have a significant impact on plant growth and morphogenesis. Parabolic flight (a zero-gravity flight mode) experiments can be performed in the earth's environment to provide microgravity conditions, although this is a very short-term technique to observe biological phenomena that occur in protracted processes such as morphogenesis and growth. Consequently, machines having a horizontal 
axis known as clinostats have become a common tool for simulating microgravity (Hoson, 2014). Clinostats, which were introduced near the end of the nineteenth century, is the most basic and least expensive technology for manipulating gravity on Earth. It simulates microgravity by taking and averaging the gravitational vector over time and simulating the absence of directional gravity input. Clinostats are divided into distinct classes based on their rotation speed and the number of rotation axes, and they are utilized in a variety of applications. The vertical axis of the organism in 1D clinostats is a continuation of the clinostat's axis of rotation; in 2D clinostats, the organism is rotated in a plane perpendicular to the axis of rotation; and in 3D clinostats, it consists of two gimbal-mounted frames rotated separately by two unique motors. Aside from clinostats, diamagnetic levitation is another method for simulating microgravity on Earth (Fig. 1). The diamagnetic levitation operating principle is based on the fact that the material to be analyzed by the force created by the magnetic field remains in the air without support (Ferranti, Del Bianco, \& Pacelli, 2021).

Figure 2: a: 1D Clinostat; b: 2D Clinostat; c: 3D Clinostat/RPM; d: Diamagnetic Levitation. Clinostats and RPMs are Devices that Employ Rotation to Counteract the Effects of Gravity on Plant Growth and Development. 1D and 2D Clinostats Rotate Around a Single Axis, whereas 3D Clinostats Rotate Around Two. Diamagnetic Levitation is a Method of Suspending an Organism in the Air Without the Need for Any External Support by Balancing the Weight of the Organism Employed in the Experiment with the Repulsive Force Imposed by a Magnetic Field. Depending on its Position in the Magnetic Field Gradient, xg; Double the Usual Gravity, $\mu$; Zero Gravity

a

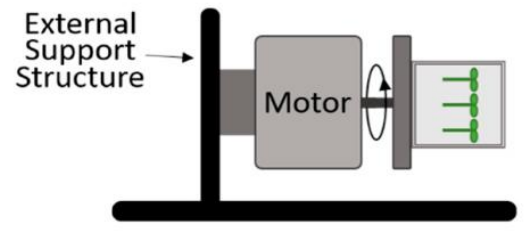

C

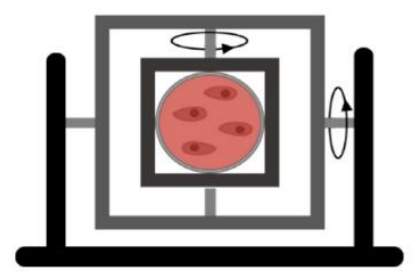

b

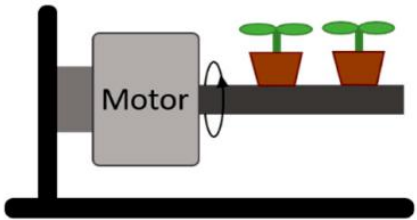

d

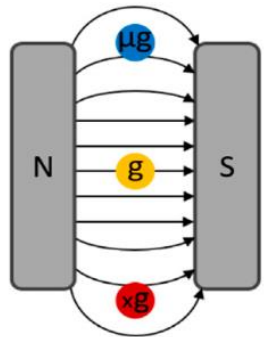

Source: Ferranti et al., 2021: 3 . 
Land plants were subjected to a variety of environmental forces during their evolution more than 400 million years ago. In the case of submersion, the force of gravity is the one that causes the most mechanical stress for plants. Underwater, the force imparted to the plant body has a much diminished impact (Hoson, Saito, Soga \& Wakabayashi, 2005). In a microgravity simulation experiment, water was used as the medium for microgravity simulation, and the development of coleoptiles was studied by submerging them in water. As a semi-aquatic plant, the rice coleoptiles employed in the experiment grew quickly and thinner than the underwater-grown version; it was discovered that despite simulating elongation, it inhibited lateral growth (Fig. 2). It has also been discovered that when rice coleoptiles are submerged, they produce different changes in the amounts and metabolism of cell wall components (Hoson, 2014).

Figure 3: Rice Seedlings Growing on Land (Left) and Rice Seedlings Growing Underwater (Right)

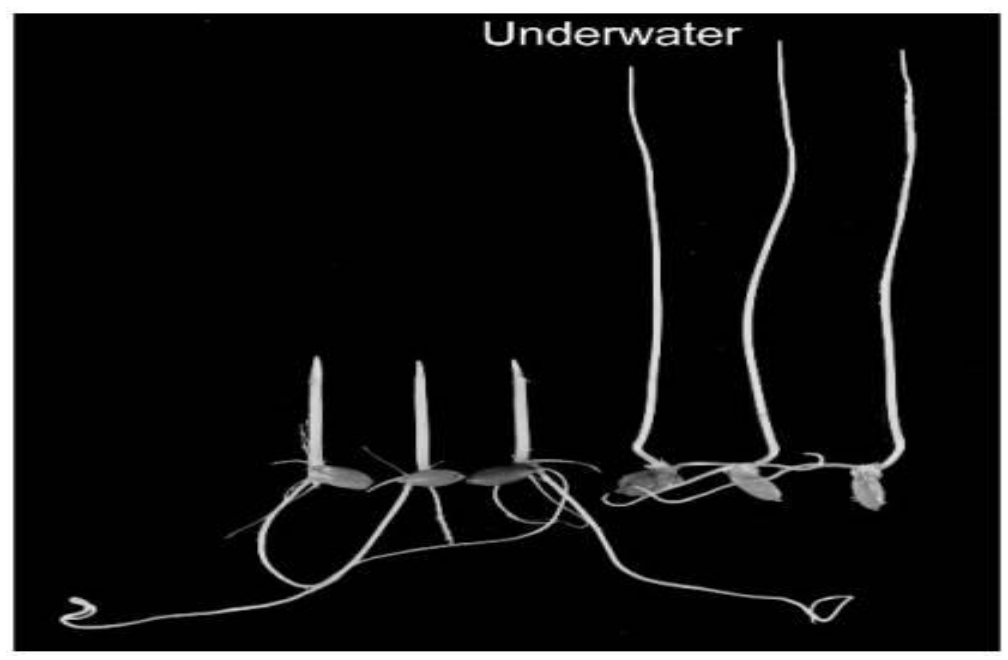

Source: Hoson, 2014: 4.

Many Many ground-based studies utilizing various types of simulators have been done in recent years to elucidate gravity's impact on plant growth and morphogenesis, and we have been able to gain great information about the gravity-dependent phenomenon using these simulator experiments. Besides all these good aspects, we may encounter some disadvantages. Many researchers have not taken the opportunity to compare their experiments on simulators with results from experiments with "real" microgravity in the space environment. Since this comparison has not been performed, and each simulator has a unique feature, it is difficult to determine both the biological reactions or the responses of the living things are caused by the simulated gravity itself or are a side effect created by the 
simulation technique (Herranz et al., 2013). Although opportunities for space research were previously restricted, the situation has substantially improved since the International Space Station's scientific operations commenced (Hoson, 2014).

An experiment called RICE on Space Shuttle STS-95 was aimed for observing changes in factors such as growth, cell wall characteristics, and morphogenesis of rice seedlings during space flight. In this experiment, rice seedlings were grown under dark conditions and the temperature difference was minimized by $0.2^{\circ} \mathrm{C}$ when compared to the ground-based experiment. When the length of coleoptile was measured, rice seedlings that grown in space were observed to be greater than in the ground seedling. When the elongation rate of coleoptiles kept frozen at $4^{\circ} \mathrm{C}$ in space was measured, it was found to be greater than that of control coleoptiles. When the mechanical characteristics of coleoptile cell walls were investigated, it was discovered that the cell wall extension of plants growing in a space environment was larger than that of control plants (Hoson et al., 2002). In another experiment, it was conducted to clarify their changes in growth by growing wild-type Arabidopsis thaliana and ethylene resistant mutant (etr1-1) hypocotyls in the dark on the Space Shuttle STS-95 (Fig. 3). As a result of these experiments, the elongation rate of Arabidopsis increased in the microgravity environment and growing under microgravity conditions seedlings gave greater lengths of hypocotyls. As a result of both experiments, we can conclude that the microgravity environment of the space environment can regulate plant elongation by increasing the plant's elongation rate (Soga, Wakabayashi, Kamisaka \& Hoson, 2002).

Figure 4: Effect of Microgravity on Elongation in Arabidopsis thaliana plants.

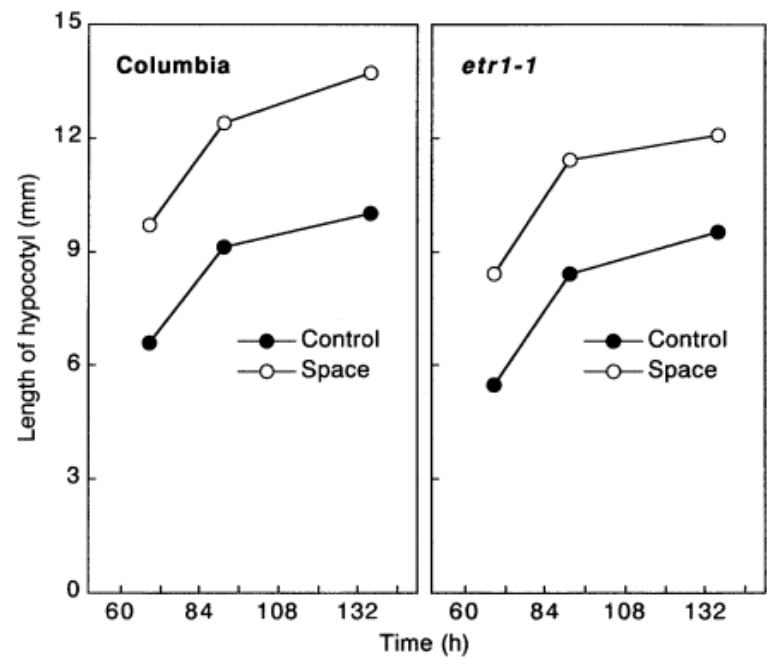

Source: Soga et al., 2002: 3. 


\subsection{Effect of Microgravity on Plant Molecular Structure}

Plants that perceive gravity as a force throughout their evolution, developed growth models with tropisms based on the gravitational vector. Plants are particularly sensitive creatures to environmental changes, even single-celled photosynthetic organisms can perceive changes in the gravitational environment. It has been observed that when plants with a coordinated system for a response to environmental changes were transferred to the International Space Station, they change their gene expression models by fine-tuning their metabolic processes with the coordinated system they have in order to adapt to this unfamiliar environment (Zupanska, LeFrois, Ferl \& Paul, 2019).

\subsubsection{Changes in heat shock proteins (hsp)}

After a period, misfolded proteins precipitate and concentrate in the cell, causing a lot of problems. Heat Shock Proteins (HSPs) arise at this phase and operate as molecular chaperones. It allows misfolded and aggregated proteins a second chance to refold properly and prevent misfolding. While HSP synthesis increases, transcription of other proteins begins to decline. This response is triggered by heat shock factors (HSFs), which are involved in the transcription of HSPmRNA (Taiz \& Zeiger, 2008).

With an experiment that conducted by Zupanska et al. (2019), it was observed that Arabidopsis plants perceived the space flight and induced gene regulation of HSPs and HSFs. Stress responses are classified as early or late at the molecular level, depending on the duration or intensity of the stimulus. Tolerance and adaptation occur against the stress factor after the responses. On the other hand, the changes in gravity that occur with space flight cause stress responses in both stages and cause the HSPs to be stimulated. Thus, it is hypothesized to play a role in cell shape preservation, along with HSP induction, by preserving the cytoskeletal architecture. 2D clinorotation were utilized to imitate microgravity in an experiment with cultures of wild-type Arabidopsis thaliana hypocotyl cells. Undifferentiated cells sense gravitation in the microgravity environment encountered during space flight, and in response to prolonged microgravity circumstances, HSP genes are activated. The experiment was carried out together with the effect of decreasing gravity in the space environment, it was observed that the most increased HSPs were Hsp17.6A, which inhibits protein aggregation, and Hsp101, which plays a role in the separation of formed protein aggregates (Zupanska, LeFrois, Ferl \& Paul, 2019). 


\subsubsection{Changes in chromosomes}

Many experiments conducted during space flight have revealed that chromosomes are negatively affected. Chromosomal abnormalities were found in the seeds of plants brought back from space and grown. In another set of spaceflight experiments, Crepis capillaris seeds showed chromosomal abnormalities and poor germination. In addition, chromosomal abnormalities in Crepis plant seeds and early maturation during Arabidopsis plant germination were observed during the 827-day space flight. Instead of attributing radiation to this condition, the researchers suggested that it is the result of a negative influence on the cellular DNA repair machinery. Thus, it has been proposed that microgravity and the time of space flight cause chromosomal damage by altering the effect of other mutagenic agents (Kitaya, 2019).

\subsubsection{Changes in meristematic cell}

Plant development begins with the vegetative stage of embryogenesis and continues throughout the plant's life. Embryogenesis establishes the plant's basic structural plan and forms meristems, which will later give rise to other organs in the mature plant. Meristems, on the other hand, provide cell growth and differentiation by their ability to divide continuously. As a result, the tissues and organs that make up the plant's overall size, shape, and structure are produced. Cell growth and division in meristems are coordinated by signals sent between different sections of plant organs. The ability to perceive and respond to these signals is known as "meristematic competence" (Taiz \& Zeiger, 2008).

The activity of meristematic cells may alter as environmental conditions change. In an experiment with lentil seedlings, results from the microgravity environment of space studies revealed a decrease in S phase and an increase in G1 phase in meristematic cells. In addition, it was requested to observe the seedling development by performing tests in three different environments. These are, during space flight, microgravity simulation with RPM machine, and $1 \mathrm{~g}$ control. RPM is a machine that eliminating the gravity vector and distributes it equally, instead of at a single point, thus causing no response to a specific gravity vector (Fig 5). Experiments were carried out with all three Arabidopsis thaliana seeds in a dark place for 4 days. As a result, for both during space flight and in RPM machine: Etiolated seedlings with high germination rate (more than 75\%), no green parts, and highly developed hypocotyls were produced (Matía et al., 2010). 
Figure 5: a; Dimensions of Arabidopsis Seedlings During Spaceflight (Left), Inside the RPM Machine (middle), and in the $1 \mathrm{~g}$ Control Medium (rigbt). b,c; Quantitative Measurement of Growth Dimensions

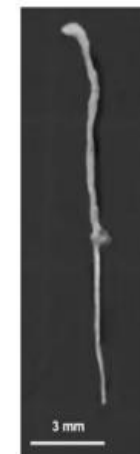

a Flight

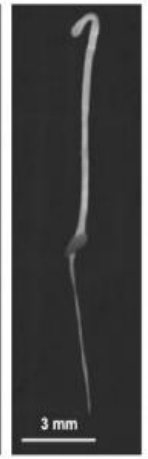

RPM

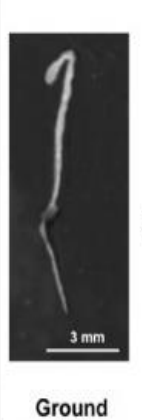

(1g) b

b

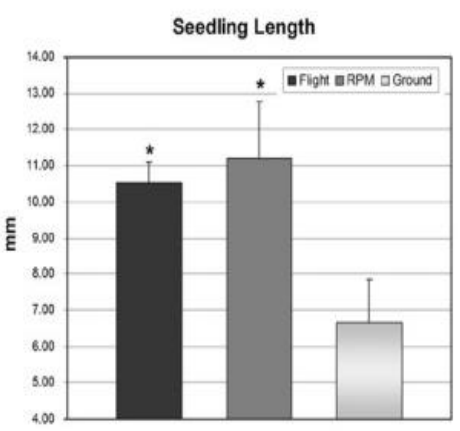

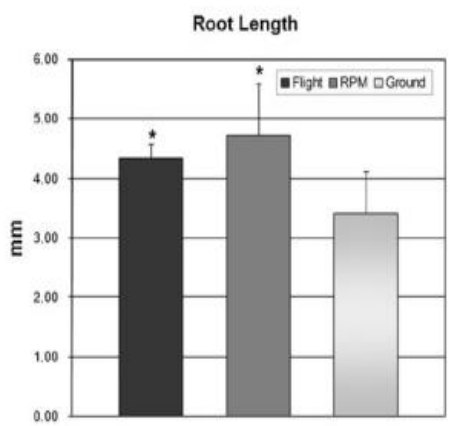

C

Source: Matia et al., 2010: 4.

\section{RADIATION EFFECTS ON PLANTS}

The space environment has got high radiation levels that can be lethal to living organisms. This high radiation nature differs from the earth's shielding nature. While the sun is our planet's primary source of radiation, this situation alters in space. To beginning, consider cosmic rays, which are composed of high-energy protons and atomic nuclei traveling very near to the speed of light. The solar proton activity, which occurs when the sun ejects high-energy protons can be given as a second example. These generate extremely high radiation levels and enough to cause death from severe radiation poisoning. Finally, we can use the energetic charged particle radiation belts (Van Allen Belts) as an example (Perez, 2017; Arena, De Micco, Macaeva \& Quintens, 2014). Several strategies have been used to study the impact of radiation on plants in spaceflight and on Earth. According to the results of space experiments, it has been discovered that plant reactions vary significantly depending on the influence of radiations kind, dose, and time (De Micco, Arena, Pignalosa \& Durante, 2011).

\subsection{Radiation Effects on Plant Genomic Material}

The more chromosomes a plant has, the more sensitive it is to radiation and the less radiation can cause damage or death. According to this, because chromosomal volume varies during cell division, the organism may react differently to radiation depending on the phase 
of these cycles. Polyploidy occurs when an organism has more than two copies of each chromosome. It is a widespread occurrence in plants, and it provides plants with an evolutionary advantage that encourages adaptation and speciation. Polyploids are shielded against the harmful consequences of mutations due to gene redundancy. Polyploidy is also known to conceal recessive mutations. As a result, any mutations that cause negative features can be concealed by a healthy allele of the same gene, allowing the organism to survive deadly circumstances. Plants' radiosensitivity is also reduced by polyploidy. In an experiment that conducted by De Micco et al. (2011), two Arabidopsis thaliana, one with a tetraploid chromosome and one with a diploid chromosome, were exposed to high LET radiation, and it was observed that the tetraploid plant lived longer than the diploid plant. Alterations in organisms' DNA generated by ionic radiation can result in a variety of phenotypic changes. These modifications have a variety of side effects, including abnormal plant growth in plant morphology, increased pubescence, physiological and cytological changes, anthocyanin accumulation, phenolic compound production, changes in photosynthetic cells, antioxidative system modulation, and thylakoid membrane expansion (De Micco et al., 2011).

In an experiment that conducted by Shui et al. (2014), the effects of radiation on the genome and epigenome were investigated in rice, treated with low and high heavy ion ground simulation and during space flight. 200 rice seeds were fixed on China's 20th recoverable satellite for 18 days, for the observing space radiation effects. On the other hand, ground-based control rice seeds were positioned in the chamber at the Heavy Ion Research Facility and it separated to two radiation group. From the spaceflight group (SP) and two radiation groups (R1 and R2), eight seeds were randomly selected for mutation rate analysis using the AFLP and MSAP methods. On the other hand, the same number of control plants from each group were also randomly selected. For the AFLP test, the average polymorphism rates of SP, R1, and R2 were respectively; $2.9 \%, 3.4 \%$, and $3.2 \%$. A significant increase in polymorphic rate was detected in all three groups when compared with their controls. The polymorphic ratios of the three groups SP, R1, and R2 treated for the MSAP test were respectively: $5.6 \%, 4.6 \%$, and $4.2 \%$. In the MSAP assay, polymorphic areas that were visible only in the spaceflight and irradiated group but not in the control group were defined as mutation areas. Four mutation sites were identified in this experiment, that used HpaII and MspI restriction enzymes. These are hyper-methylation in the CG region, hyper-methylation in the CNG region, hypo-methylation in the CG region, and hypo-methylation in the CNG region. According to the data that they had, all of these mutations were found in both the spaceflight and radiation groups. While more than half of the mutations in the radiation 
groups occurred in the CG region, the CNG mutation was more common in the space flight group. With these results, it has been suggested that space flight could induce the epigenome. Even though the mutation rates of rice in spaceflight and on the ground were similar, the location of mutations in the genome differed between the radiation groups. Two factors have been proposed as the cause of this difference. To begin with, although radiation is simulated on Earth in the experiment, the types of radiation that exist in space have become more complex and diverse. As a result, the mutagenesis effects on the genome of the living organism vary. Second, it is suggested that the microgravity and magnetism of the space environment can increase the effects of radiation on living organisms (Shi, Lu \& Sun, 2014).

\subsection{Radiation Effects on Plant Morphology}

Along with the researches, it has been found that radiation causes physiological changes in living organisms by damaging components such as DNA. With an increase in radiation level, the amount of reactive oxygen species (ROS) increases in the cell. ROS can initiate free radical chain reactions in which various free radicals are formed and cause the formation of various free radicals in the cell such as carbon-centered organic radicals, peroxide radicals, alkoxy radicals, thiyl radicals, sulfenyl radicals. For example, after gamma irradiation, the accumulation of hydrogen peroxide $\left(\mathrm{H}_{2} \mathrm{O}_{2}\right)$, a key component of ROS, increased, especially in the plasma membranes of leaf tissues and in the middle lamellae. Living organisms have an endogenous enzyme defense mechanism that includes superoxide dismutase, peroxidase, and catalase to defend themselves from and control the potentially harmful effects and damage of ROS (Wi et al., 2007). These endogenous enzymes that provide defense against ROS emerge with a tissue and plant-specific response in resistance to radiation. In addition, plants may be more resistant to radiation alongside a prokaryotic organism because their genetic material is membrane-enclosed, and they have more complicated organelle organizations than prokaryotes. Furthermore, phenolic compounds are secondary metabolites generated by plants that include one or more hydroxyl groups connected to the benzene ring and functional group. These compounds, which can be found in the fruit portions of plants too for providing taste, primarily defend the plant when it is subjected to stressful circumstances. Phenolic compounds, which contain flavonoids, phenolic acids, tannins, stilbenes, and lignins, provide an excellent defensive mechanism for plants against radiation. It is also known that trichomes in plant epidermis play a function in protecting the plant's meristem and shielding the plant from UV rays (Fig. 6) (Arena et al., 2014). 
Figure 6: Properties that Gives to Plants Radio-resistance.

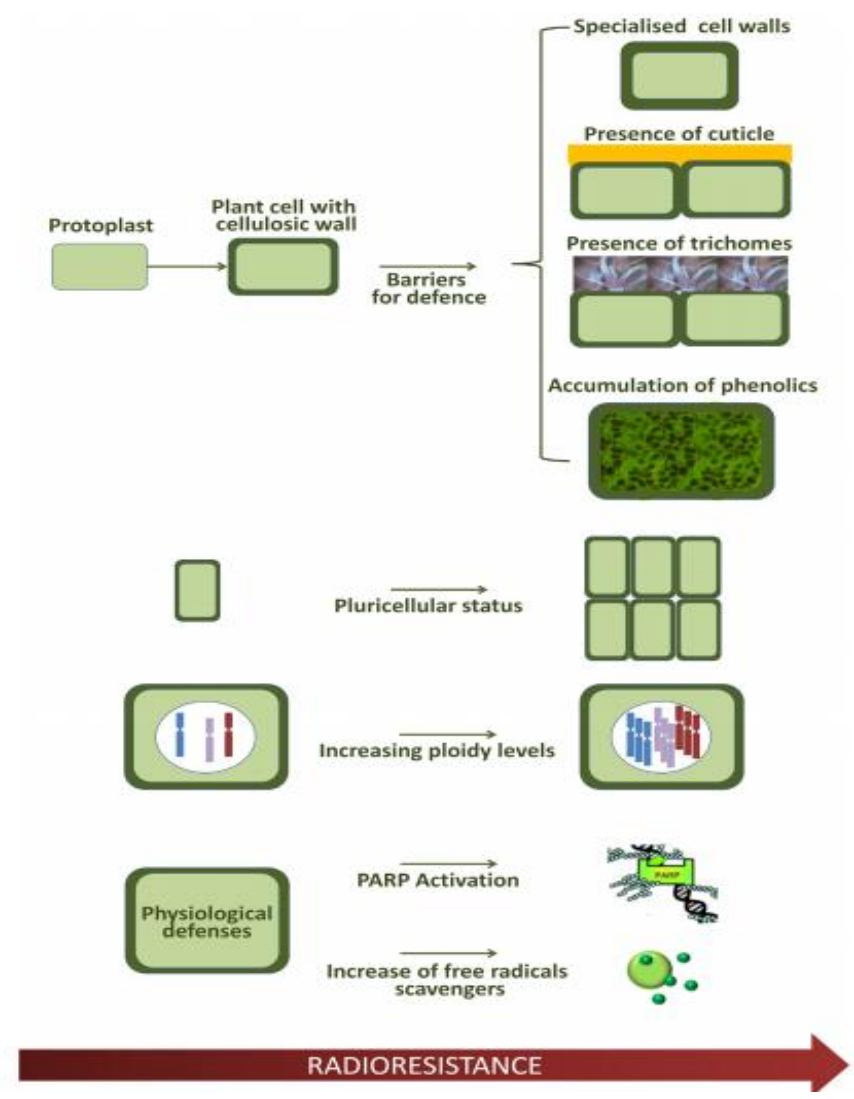

Source: Arena et al., 2014: 7.

In an irradiation experiment that conducted by Wi et al. (2005), with high x-ray doses at 50 and $100 \mathrm{~Gy}$, reduced growth of bean plants was observed. After irradiation, although flower development was observed in the plants and chlorosis and tissue necrosis did not occur, a great decrease in stem elongation and leaf growth was observed. In another experiment, it was observed that Arabidopsis plants exposed to low dose (1-5 Gy) irradiation showed a typical structure with arranged thylakoid membranes of different grana and stroma regions with an ellipsoidal shape compared to control plants. On the contrary, when exposed to a high dosage of $50 \mathrm{~Gy}$ irradiation, the normal shape of chloroplasts altered dramatically, their thylakoid membranes were destroyed, and numerous plastoglobulin and starch grains appeared. Damage and disorientation of the grana and thylakoids, as well as restriction of carbohydrate transport, were seen in association with these deposits. However, there was no apparent difference in chloroplast size and structure between low- and high-dose irradiated plants. Aside from the change in photosynthetic apparatus, no change in mitochondria was observed after low-dose irradiation, however, this condition altered after high-dose 
irradiation, resulting in distorted mitochondria, and swollen endoplasmic reticulums in the plant. Furthermore, no damage to the nuclear envelope was found at both high and low irradiation levels (Fig. 7) (Wi et al., 2005).

Figure 7: Phenotypes of Arabidopsis of Control (Left) and Treated After 6 Days with 50 Gy (Right) Gamma Irradiation

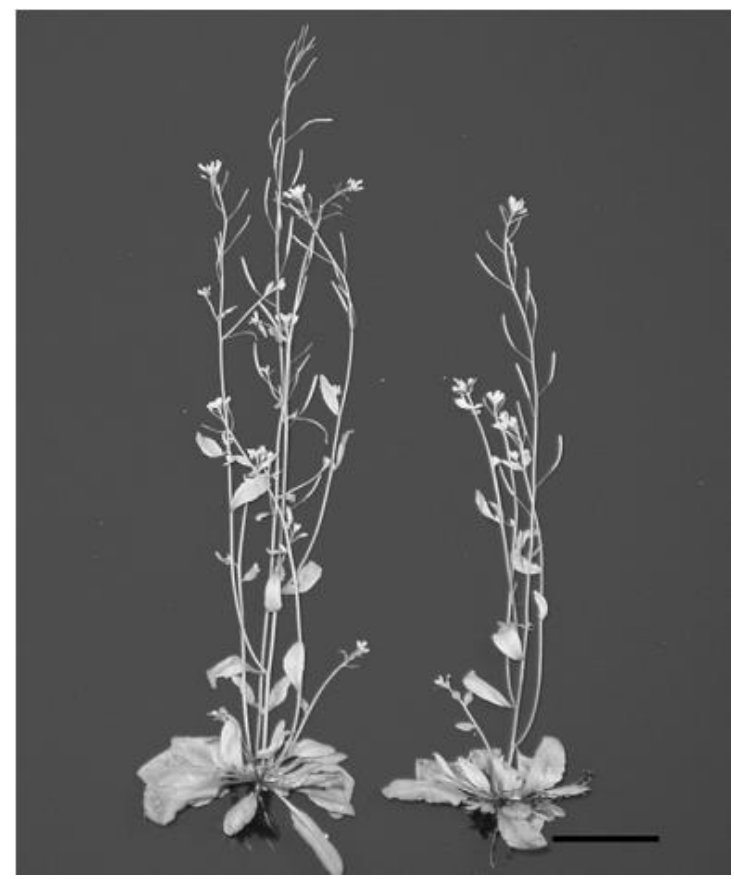

Source: Wi et al., 2005: 2.

Pectins are the most radiosensitive molecules among the matrix components. With its degradation, we can see the dissolution of the middle lamellae visibly. With the dissolution of the middle lamella, the pores that support tissue softening and water absorption are increased. Radiation-induced change in cell wall materials will reduce mechanical constraints during turgor pressurized cell expansion. Thus, there will be an increase in the cell size of the leaves exposed to radiation. Although mechanical protection or metabolic responses cannot prevent cell/tissue/organ degradation, plants are adaptable organisms that can continue to develop and are more likely than mammals to survive radiation exposure (Arena et al., 2014).

\subsection{Radiation Effects on Plant Morphology}

Photosynthesis is a physiological mechanism that affects plant development directly and is extremely susceptible to environmental stress. Along with the experiments, it has been revealed that $\mathrm{X}$-rays, gamma rays, and heavy ions cause damage to the photosynthetic apparatus of the plant. Therefore, such damage also suppresses photosynthesis. The major 
cause of this damage due to the photosystem II (PSII) complex's susceptibility to radiation damage. Photosystems (PSI and PSII), located on thylakoid membranes; are systems made up of chlorophyll, proteins, and other smaller inorganic molecules. PSII, one of these photosystems, is a complex of various pigments and proteins found in both higher plants and cyanobacteria, with the electron transporter plastoquinone, which transfers electrons by water oxidation. It consists of more than 25 polypeptides in its complex structure. The primary antenna complex is that the light-harvesting chlorophyll protein complex, which collects light energy and transports it to the chlorophyll reaction center (P680). Second, the oxygen-evolving complex (OEC) is the site of photo-oxidation in water. Finally, D1 and D2 proteins are found in the PSII reaction center as heterodimers. Because the D1 protein is the primary target of radiation stress, we can obviously observe radiation-induced damage in the PSII region (Rea et al., 2008).

In ultrastructural studies on the peel of banana fruit, induced expansions between thylakoid membranes and losses in grana stacks were observed at exposures above $0.2 \mathrm{kGy}$ with gamma irradiation. Ionizing radiation has also been demonstrated to suppress chlorophyll production in etiolated wheat and barley leaves, as well as potato tubers. In addition, $1 \mathrm{kGy}$ gamma irradiation changed the chloroplast structure in fruits containing chloroplasts in their hypodermis at harvest time. The plastids of the maintained control plant became senescent, with few distinct plastoglobulins and faintly colored inner membranes. The plastids preserved a large amount of their inner membrane as somewhat inflated thylakoids packed with an electron-dense material in the group of plants exposed to irradiation during storage. The grana stacks were even absent in some plastids. Based on the findings, it was expected that irradiation affects plastids in two ways: first, it inhibits senescence, and second, it causes dedifferentiation in the agranal stage (Kovacs \& Keresztes, 2002). Another experiment with the Phaseolus vulgaris, revealed that the photosynthetic apparatus efficiency decreased after being exposed to high levels of irradiation around $50 / 100 \mathrm{~Gy}$, resulting in a considerable drop in total chlorophyll content. The reduction in photosynthetic pigments was assumed to be a negative outcome of oxidative stress induced by free radicals as a result of ionizing irradiation. At the anatomical level, high-dose radiation had no negative impact on the leaf structures of Phaseolus vulgaris. Exposure to large doses of $\mathrm{X}$-rays, on the other hand, boosted the synthesis of phenolic chemicals. High phenolic levels are well recognized to give radiation resistance to plants and successfully protect cells from DNA damage. Aside from all of these experiments, it is known that the seed phase is more radiation-resistant than the other phases of plants life. On the other hand, because water 
deprivation decreases radiolysis and the overproduction of free radicals, dried seeds are more radiation-resistant (Arena et al., 2013).

\section{OPTIMUM LIGHTING FOR PLANTS IN SPACE}

\subsection{Effects of Light on Plants}

Light has a variety of affects on plant life. To begin with, plants are photosynthetic organisms that require light to generate energy. They can also use the power of light to grow. In addition to all these two, light acts as a morphogenic signal, controlling several plant processes. Finally, it participates in a variety of light-dependent metabolic processes in the plant (Fig. 8). Light, for example, causes the production of phytochrome hormones, which play a vital role in plant growth and development. The plant's pigments absorb light energy and send it to the reaction center; all of these pigments are found within the chloroplasts. The proteins required for photosynthesis are found within the thylakoid membranes. In thylakoid membranes, chlorophylls and light-gathering accessory proteins are attached to proteins by very special bonds. As a result of this special bonding, the energy transferred in the antenna complexes and electron transfer is carried out in the reaction center in an optimum way (Berkovich et al., 2017).

Figure 8: Role of Light in the Plant Life

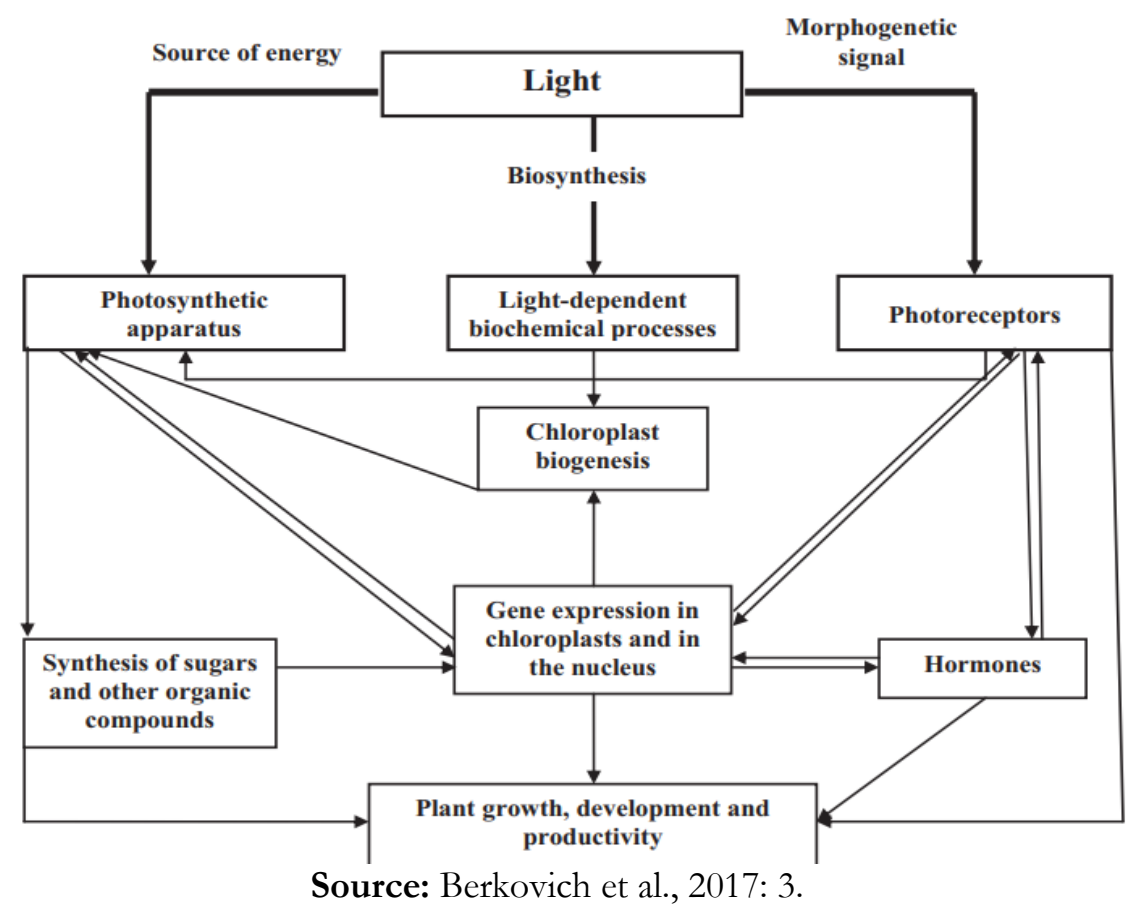




\subsection{LED Lighting Systems and Reactions in the Plant}

There are three important advantages of working with LED in plants: First of all, there is no need for electronic ballasts used to limit the amount of current in the electrical circuit like other light sources (e.g. fluorescence), it offers the flexibility to choose monochromatic light and different wavelengths and it can be used in small areas without problem proximity to the plant, owing to its very low heat emission (LED Systems Target Plant Growth., nd). For an example for these advantages of LED systems: VEGGIE (Vegetable Production System) are small vegetable production rooms where NASA developed the concept of using photosynthetic higher plants to provide bioregenerative life support for NASA astronauts during long-duration space flights (Fig. 9). The LED lighting system is the source of plant growth in these rooms (Burgner et al., 2020).

Figure 9: "Veggie" Vegetable Production Unit on the International Space Station.

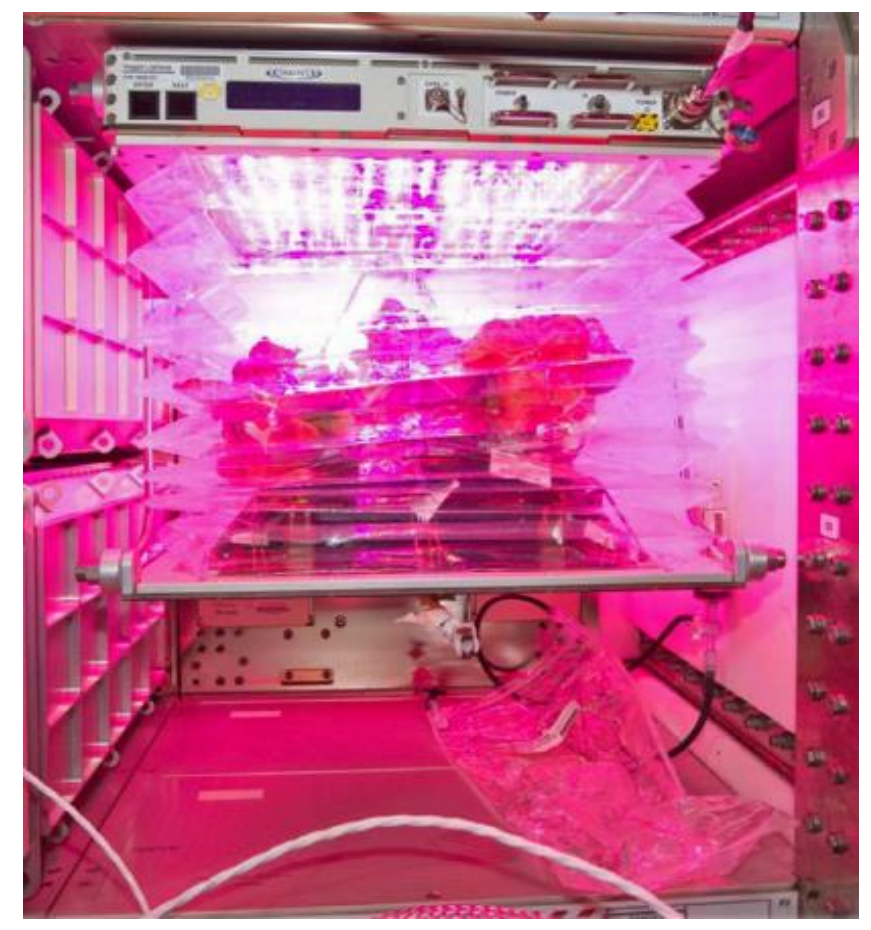

Source: Burgner et al., 2020: 2.

Besides from Led lighting system, we can use high-pressure sodium or metal halide to cultivate plants too, but different types of lamps provide different proportions of radiant flux, which affects both photosynthetic efficiency and thermal balance. Parallel to this, when compared to LED light sources, it is required to place them at more remote points to avoid damaging plants. Thus, additional working power is required to produce sufficient 
photosynthetic photon flux (PPF) at the leaf level (Bula et al., 1991). Let's go through this topic in detail with an experiment. Photosynthetic photon flux (PPF) is a unit of measurement that represents the overall quantity of photosynthetically active radiation generated by the lighting system once per second. The purpose of this experiment was to evaluate the quality of the LED light system by exposing the Chinese cabbage grown in space to continuous red $(650 \mathrm{~nm})$ and blue $(470 \mathrm{~nm})$ rays. Control plants were cultivated with high-pressure sodium lights. A set of plants developed with PPF 100 were transported to a point where the PPF ratio was 400, and the differences in PPF ratios were controlled. In addition, three unique parameters of chlorophyll fluorescence, indicative of photosynthetic energy conversion, were computed: PSII quantum yield (Fv/Fm), photochemical fluorescence quenching (qP), and non-photochemical fluorescence quenching (NPQ). The following are the results of the PPF 100 plant assessments: There were no significant variations in photosynthetic pigment content on the 15th day when compared to control plants grown with HPS lamps; however, plants cultivated with LEDs had higher Fv / Fm, NPQ, and photophosphorylation rate than plants grown with HPS lamps. While no change in the Fv/FM ratio was observed on the 28th day, the NPQ ratio was less than the photophosphorylation ratio in LED plants, and the rate of photophosphorylation was percentage times higher. As a result of this phenomenon, plants grown under LED light have a very high energy storage capacity during photosynthesis. When the experiments were carried out with the PPF400, the differences between the control and the plants growing under LED light were more apparent. The outcomes are as follows. LED plants produced more photosynthetic pigment than control plants. The photosynthetic system is anticipated to adjust to the altered illumination circumstances as a result of this situation. Surprisingly, the rate of photophosphorylation in the control plants' leaves was two times lower than in PPF100. Furthermore, a high shoot/root dry weight ratio was discovered in plants grown under LED on the 28th day, indicating that the plant's organ development was unbalanced. In all of the results obtained, the chlorophyll concentration did not respond to the light spectrum and hence did not suggest changes in plant production. The photophosphorylation rate, on the other hand, was the greatest and varied with PPF and light spectrum. More research into the development of LED illumination sources for plant growth and yield must quantify the finer physiological parameters that affect plant yields, such as plant hormone activity and cell homeostasis. Employing LED lights, it may be feasible to influence physiological processes in the greenhouse by using light sources with different spectrums. As 
a result, it may generate a variety of light sources that are most useful in a variety of applications (Avercheva et al., 2014).

\section{RESULT}

We aimed to examine the impacts of space environment conditions on plants in this review by bringing together key studies and observations. The following are the broad conclusions taken from these effects: Plants have exhibited a resistance mechanism to all of these tough environments, as demonstrated by experiments wherein long-term space journeys or tough circumstances such as microgravity and radiation are simulated. For example, despite a decrease in response due to microgravity conditions, the plant was still able to perform gravitropism movement, there was no loss in the cell structures and functions of the leaves, only the shape and position of the cell changed with environmental factors, and when exposed to high levels of X-rays, these tiny greens stimulated the production of phenolic compounds as natural shields against radiation. As a consequence, we may infer that the growth and development model is an intrinsic genetic ability for plants and that environmental factors determine whether this innate genetic ability develops in a positive or negative direction. The plant's capacity to detect the environmental change and adapt to it in order to live is beneficial to both present and future astrobotanical research. Almost all research encountered difficulties, but these obstacles did not prevent plant development in space. As space exploration increases and technology develops, astrobotanical studies will progress parallel within. We believe that the overtime, many different planets will be discovered in other stars. Such as Earth-like planets, oceanic planets formed entirely of water, planets like Mars that have lost their atmosphere because of solar wind influence, and planets like Venus that have distributed their seas into deep space with uncontrolled greenhouse effects... With these increasing discoveries, both astrobiology and astrobotanical research, which recycles the habitability of these flights, will increase every year.

\section{REFERENCES}

Arena, C., De Micco, V., Aronne, G., Pugliese, M., De Santo, A. V., \& De Maio, A. (2013). Response of Phaseolus vulgaris L. plants to low-let ionizing radiation: growth and oxidative stress. Acta Astronautica, 91, 107-114. https://doi.org/10.1016/j.actaastro.2013.05.013

Arena, C., De Micco, V., Macaeva, E., \& Quintens, R. (2014). Space radiation effects on plant and mammalian cells. Acta Astronautica, 104(1), 419-431.

https://doi.org/10.1016/j.actaastro.2014.05.005 
Life of Plants In Space: A Challenging Mission For Tiny Greens In An Everlasting Darkness Ecem Su KOÇKAYA-Cemal ÜN

Avercheva, O., Berkovich, Y. A., Smolyanina, S., Bassarskaya, E., Pogosyan, S., Ptushenko, V., ... \& Zhigalova, T. (2014). Biochemical, photosynthetic and productive parameters of Chinese cabbage grown under blue-red LED assembly designed for space agriculture. Advances in space research, 53(11), 1574-1581. https://doi.org/10.1016/j.asr.2014.03.003

Barker, R., \& Gilroy, S. (2017). Life in space isn't easy, even if you are green. The Biochemist, 39(6), 10-13. https://doi.org/10.1042/BIO03906010

Berkovich, Y. A., Konovalova, I. O., Smolyanina, S. O., Erokhin, A. N., Avercheva, O. V., Bassarskaya, E. M., ... \& Tarakanov, I. G. (2017). LED crop illumination inside space greenhouses. Reach, 6, 11-24. doi:10.1016/j.reach.2017.06.001.

Bula, R. J., Morrow, R. C., Tibbitts, T. W., Barta, D. J., Ignatius, R. W., \& Martin, T. S. (1991). Light-emitting diodes as a radiation source for plants. HortScience, 26(2), 203-205. https://doi.org/10.21273/HORTSCI.26.2.203

Burgner, S. E., Nemali, K., Massa, G. D., Wheeler, R. M., Morrow, R. C., \& Mitchell, C. A. (2020). Growth and photosynthetic responses of Chinese cabbage (Brassica rapa L. cv. Tokyo Bekana) to continuously elevated carbon dioxide in a simulated Space Station "Veggie" crop-production environment. Life Sciences in Space Research, 27, 83-88. https://doi.org/10.1016/j.lssr.2020.07.007

De Micco, V., Arena, C., Pignalosa, D., \& Durante, M. (2011). Effects of sparsely and densely ionizing radiation on plants. Radiation and Environmental Biophysics, 50(1), 1-19. doi:10.1007/s00411-010-0343-8

Ferranti, F., Del Bianco, M., \& Pacelli, C. (2021). Advantages and Limitations of Current Microgravity Platforms for Space Biology Research. Applied Sciences, 11(1), 68. https://doi.org/10.3390/app11010068

Herranz, R., Anken, R., Boonstra, J., Braun, M., Christianen, P. C., de Geest, M., ... \& Hemmersbach, R. (2013). Ground-based facilities for simulation of microgravity: organism-specific recommendations for their use, and recommended terminology. Astrobiology, 13(1), 1-17. https://doi.org/10.1089/ast.2012.0876

Hoson, T. (2014). Plant growth and morphogenesis under different gravity conditions: relevance to plant life in space. Life, 4(2), 205-216. https://doi.org/10.3390/life4020205

Hoson, T., Saito, Y., Soga, K., \& Wakabayashi, K. (2005). Signal perception, transduction, and response in gravity resistance. Another graviresponse in plants. Advances in Space Research, 36(7), 1196-1202. https://doi.org/10.1016/j.asr.2005.04.095

Hoson, T., Soga, K., Mori, R., Saiki, M., Nakamura, Y., Wakabayashi, K., \& Kamisaka, S. (2002). Stimulation of elongation growth and cell wall loosening in rice coleoptiles under microgravity conditions in space. Plant and Cell Physiology, 43(9), 1067-1071. https://doi.org/10.1093/pcp/pcf126

Kitaya, Y. (2019). Plant Factory and Space Development,“Space Farm”. In Plant Factory Using Artificial Light (pp. 363-379). Elsevier. https://doi.org/10.1016/B978-0-12-813973-8.00030-0

Kovacs, E., \& Keresztes, A. (2002). Effect of gamma and UV-B/C radiation on plant cells. Micron, 33(2), 199-210. https://doi.org/10.1016/S0968-4328(01)00012-9

Matía, I., González-Camacho, F., Herranz, R., Kiss, J. Z., Gasset, G., van Loon, J. J., ... \& Medina, F. J. (2010). Plant cell proliferation and growth are altered by microgravity conditions in spaceflight. Journal of plant physiology, 167(3), 184-193. doi: 10.1016/j.jplph.2009.08.012

Mochizuki, S., Harada, A., Inada, S., Sugimoto-Shirasu, K., Stacey, N., Wada, T., ... \& Sakai, T. (2005). The Arabidopsis WAVY GROWTH 2 protein modulates root bending in response to environmental stimuli. The Plant Cell, 17(2), 537-547. https://doi.org/10.1105/tpc.104.028530 
Life of Plants In Space: A Challenging Mission For Tiny Greens In An Everlasting Darkness Ecem Su KOÇKAYA-Cemal ÜN

Muthert, L. W. F., Izzo, L. G., Van Zanten, M., \& Aronne, G. (2020). Root tropisms: Investigations on earth and in space to unravel plant growth direction. Frontiers in plant science, 10, 1807. https://doi.org/10.3389/fpls.2019.01807

NASA, LED Systems Target Plant Growth. (n.d.). Retrieved 2021, from https://spinoff.nasa.gov/Spinoff2010/cg 1.html

NASA, Perez, J. (2017, April 13). Why Space Radiation Matters. Retrieved 2021, from https://www.nasa.gov/analogs/nsrl/why-space-radiation-matters

Rea, G., Esposito, D., Damasso, M., Serafini, A., Margonelli, A., Faraloni, C., ... \& Giardi, M. T. (2008). Ionizing radiation impacts photochemical quantum yield and oxygen evolution activity of Photosystem II in photosynthetic microorganisms. International journal of radiation biology, 84(11), 867-877. https://doi.org/10.1080/09553000802460149

Rehman, M., Ullah, S., Bao, Y., Wang, B., Peng, D., \& Liu, L. (2017). Light-emitting diodes: whether an efficient source of light for indoor plants?. Environmental Science and Pollution Research, 24(32), 24743-24752. https://doi.org/10.1007/s11356-017-0333-3

Shi, J., Lu, W., \& Sun, Y. (2014). Comparison of space flight and heavy ion radiation induced genomic/epigenomic mutations in rice (Oryza sativa). Life sciences in space research, 1, 74-79. https://doi.org/10.1016/j.lssr.2014.02.007

Soga, K., Wakabayashi, K., Kamisaka, S., \& Hoson, T. (2002). Stimulation of elongation growth and xyloglucan breakdown in Arabidopsis hypocotyls under microgravity conditions in space. Planta, 215(6), 1040-1046. https://doi.org/10.1007/s00425-002-0838-x

Stutte, G. W., Monje, O. S. C. A. R., Hatfield, R. D., Paul, A. L., Ferl, R. J., \& Simone, C. G. (2006). Microgravity effects on leaf morphology, cell structure, carbon metabolism and mRNA expression of dwarf wheat. Planta, 224(5), 1038-1049.

Türkan, İ., (Ed.). (2008). Bitki Fizyolojisi (3rd ed.). Ankara: Taiz, L., Zeiger, E.

Vandenbrink, J. P., \& Kiss, J. Z. (2016). Space, the final frontier: A critical review of recent experiments performed in microgravity. Plant Science, 243, 115-119.

https://doi.org/10.1016/j.plantsci.2015.11.004

Wi, S. G., Chung, B. Y., Kim, J. H., Baek, M. H., Yang, D. H., Lee, J. W., \& Kim, J. S. (2005). Ultrastructural changes of cell organelles in Arabidopsis stems after gamma irradation. Journal of Plant Biology, 48(2), 195-200. https://doi.org/10.1007/BF03030408

Wi, S. G., Chung, B. Y., Kim, J. S., Kim, J. H., Baek, M. H., Lee, J. W., \& Kim, Y. S. (2007). Effects of gamma irradiation on morphological changes and biological responses in plants. Micron, 38(6), 553-564.) doi: 10.1016/j.micron.2006.11.002

Zupanska, A. K., LeFrois, C., Ferl, R. J., \& Paul, A. L. (2019). HSFA2 functions in the physiological adaptation of undifferentiated plant cells to spaceflight. International journal of molecular sciences, 20(2), 390. https://doi.org/10.3390/ijms20020390 